\title{
Educational Materials for High School Summer Engineering Programs
}

\author{
*Dr. H. Estrada, P. E. (corresponding author) and *Dr. P. Leelani, P. E. \\ *Civil Engineering Program \\ Texas A\&M University - Kingsville \\ MSC 194 \\ Kingsville, Texas 78363 \\ Hector.Estrada@tamuk.edu
}

\begin{abstract}
It is well known that the main reason many students do not pursue careers in engineering is because they are not aware of the opportunities available or simply do not know engineering is something other than conducting trains. In this paper, we present materials developed for a summer engineering program to educate high school students about the academic and professional opportunities engineering has to offer. The educational materials have been used the last three summers and 49 high school students have participated. The students are selected from several area high schools based on their academic interest, with the highest priority given to those interested in mathematics and science. They are brought to Kingsville to experience college life (including college admission and other college related activities) and to participate in several educational activities designed to familiarize them with civil engineering, including construction materials, structural engineering, transportation, environmental engineering, and water resources engineering. The primary objective of the material is to expose high school students to the great opportunities the profession of civil engineering has to offer.

The program has been a success, with one of the participants enrolling in the Civil Engineering Program at TAMUK following the institute in the fall of 2002, three of the participants from 2002 enrolling in the fall of 2003 and one from the summer of 2003 enrolling in the fall of 2004. This is particularly important because these students had plans to enter a different discipline and were not aware of any engineering careers! Furthermore, all but one of the remaining participants from 2002 have indicated that they would pursue a career in engineering. From the 2004 group, several participants have inquired about entering engineering next summer. There is no doubt that the educational materials have provided these students sufficient information to make an educated decision to pursue a degree in engineering.
\end{abstract}

\section{Introduction}

Most students who know anything about engineering perceive this academic field as "very 
difficult" and "very demanding"; fun is usually not an attribute associated with engineering. Furthermore, due to wide availability of opportunities for college-bound students, engineering is usually not their top choice. With engineering enrollment on the decline and demand for engineers on the rise, it is imperative that we make all high school students aware of the profession of engineering. Also, it is important to expose all potential students to the opportunities of a college education. The activities presented in this paper can be used to expose undecided high school students to the great opportunities the profession of engineering has to offer.

The activities are intended for all high school students and have been tested with students from the $8^{\text {th }}$ through the $12^{\text {th }}$ grades, male and female, and with different levels of academic preparation $^{1}$. Our experience has shown that this has also helped students in the critical years $\left(8^{\text {th }}\right.$ and $9^{\text {th }}$ grades), when a large percentage drops out of school. The first year, the participants were selected based on their academic interests and with the recommendation of their school counselor. The last two years, an application process was used and students were selected based on gender to arrive at a particular distribution of male and female participants. Also, priority was given to those students with the highest achievement in mathematics and science, particularly those who had participated in science competitions. Based on these criteria, offers to participate in the institute were extended to approximately 15 to 20 students per summer. In the first summer 15 students were invited and agreed to participate, and all showed up. In the past two summers, offers were extended to 20 students each summer; however, in the summer of 2003 only 16 showed up, and in the summer of 2004 only 18 showed up. The reason for this is that the first summer the participants were selected and interviewed prior to arriving in Kingsville; the last two summers no such an effort was made. To improve the acceptance rate, it is advisable to make phone contact with the participants prior to the start of the program.

A summer program should provide participants hands-on problem solving activities to enhance their appreciation for mathematics and science, as well as an introduction to the civil engineering profession. The activities presented here are for a project lasting two weeks, including group counseling, advisement on the college application process, financial aid, and technical activities. The technical activities emphasize hands-on civil engineering projects, interaction of participants with practicing engineers, and discussion of different engineering disciplines with engineering faculty. To provide real life engineering experience, activities including field trips to engineering work sites were provided.

\section{Objectives of the TAMUK Institute}

$\checkmark$ Expose participants to post secondary campus life as well as career opportunities in engineering and other activities usually not available to disadvantaged and other youth in economically depressed geographic regions,

$v$ Familiarize participants with civil engineering,

$v$ Discuss college admissions and other requirements, as well as financial assistance,

$v$ Most importantly, provide participants with hands-on problem solving activities to enhance their appreciation for mathematics and science. 


\section{Outreach Programs at Other Universities}

The vast majority of the summer programs for high school students found at other institutions emphasize science and mathematics ${ }^{2}$. There are other programs that discuss engineering and emphasize elementary projects not related to engineering practice ${ }^{3}$. A summary of the assessment of K-12 pre-engineering outreach programs is given by Poole et al. $(2001)^{4}$. Most of the discussion in all of these cases emphasize elementary science and mathematics. The program conducted at TAMUK uses real life practical civil engineering projects condensed into daylong activities to give the participants an appreciation for mathematics and science. This is the reverse of what other programs do where mathematics and science are presented as the foundation for engineering with no connection to practical projects to elucidate the reason for studying math and science.

\section{Civil Engineering Activities}

The primary focus of the activities is on civil engineering. The activities are designed to be hands-on, non-repetitive so that the students' interest is maintained for the duration of the activity. The activities cover a broad spectrum of the civil engineering discipline including transportation, structures, materials, water resources, wastewater and water treatment projects as well as field trips to area construction and other sites. Most of the activities consist of a brief discussion of the related applications and a hands-on project, which can be carried out by small groups. Some of the activities are complemented by field trips to actual engineering work sites. Throughout all projects, the importance of science, mathematics, and computers were emphasized.

The participants resided on campus for the duration of the program. Most of the activities were conducted in the Civil Engineering Laboratory. The costs of room, board, and other costs related to the activities and prizes, were covered from public and private funds. Following is a brief description of typical activities.

\section{Introduction and Advisement}

The first day, participants were directed to the dormitories to situate themselves. A coordinator assisted with the logistics of room and board. A brief introduction was made by the director, including a discussion and overview of the program. Also, with the guardians present, a presentation about the nightly activities and the dormitory and other rules should be made. For the first day, the program staff and the participants typically had lunch together.

The advisement component of the project included discussions from university personnel regarding college opportunities, university admissions process, different financial assistance programs available, career counseling, nutrition counseling, and college life in general. Arrangements were made for participants to receive complementary student identifications to allow them to use the sports facilities and other facilities on campus. The first day typically concludes by giving the participants a tour of campus and student facilities.

\section{Construction Materials}

The participants were asked to arrive at a predetermined location at an appropriate time in the 
morning to begin the day's activities. The day began by discussing materials for construction including concrete, steel, timber, asphalt, soil, and fiber-reinforced composites. Several show-and-tell objects were used to illustrate the use of these materials in construction: concrete canoe, steel bridge for Steel Bridge Competition, lumber, carbon and glass reinforced plastic. A compression test on a concrete cylinder is usually performed to give the participants an appreciation of material strength.

In the afternoon, after a discussion on the ingredients and properties of concrete, the participants are divided into groups of three to five members. Each group is responsible for mixing a batch of concrete and fabricating three to five concrete cylinders. The object of the activity is to produce the strongest concrete using different aggregates and additives. These specimens are tested in compression on the last day of the program. The group with the strongest concrete wins a prize.

\section{Spot Speed Study}

The participants are asked to arrive at a predetermined location at an appropriate time in the morning to begin the day's activities. The day begins by discussing the importance of transportation engineering, particularly traffic engineering, crashworthiness and crash survivability. The importance of following speed limits is stressed. This is particularly important since we are dealing with inexperienced drivers and some future drivers. The participants are then divided into groups of three members each. Each group then conducts a spot speed study along a road near campus using a radar gun. The radar gun is borrowed from the university police department and is used in conformance with the law. Each group obtains 40 to 50 readings (representative) over an hour period. Each team takes turns collecting their spot speed data.

The data is then analyzed using statistical methods with MS-Excel to determine if posted speed limits are obeyed. Each group produces a cumulative speed distribution curve (so-called S-curve ${ }^{2}$ ), see figure. With this curve, the students are asked to identify the average speed and the 85-percentile speed. The results should indicate if traffic moves at the posted speed limit. This activity was also a competition, and engineering faculty are asked to evaluate the reports to determine the best report. The winners receive prizes.

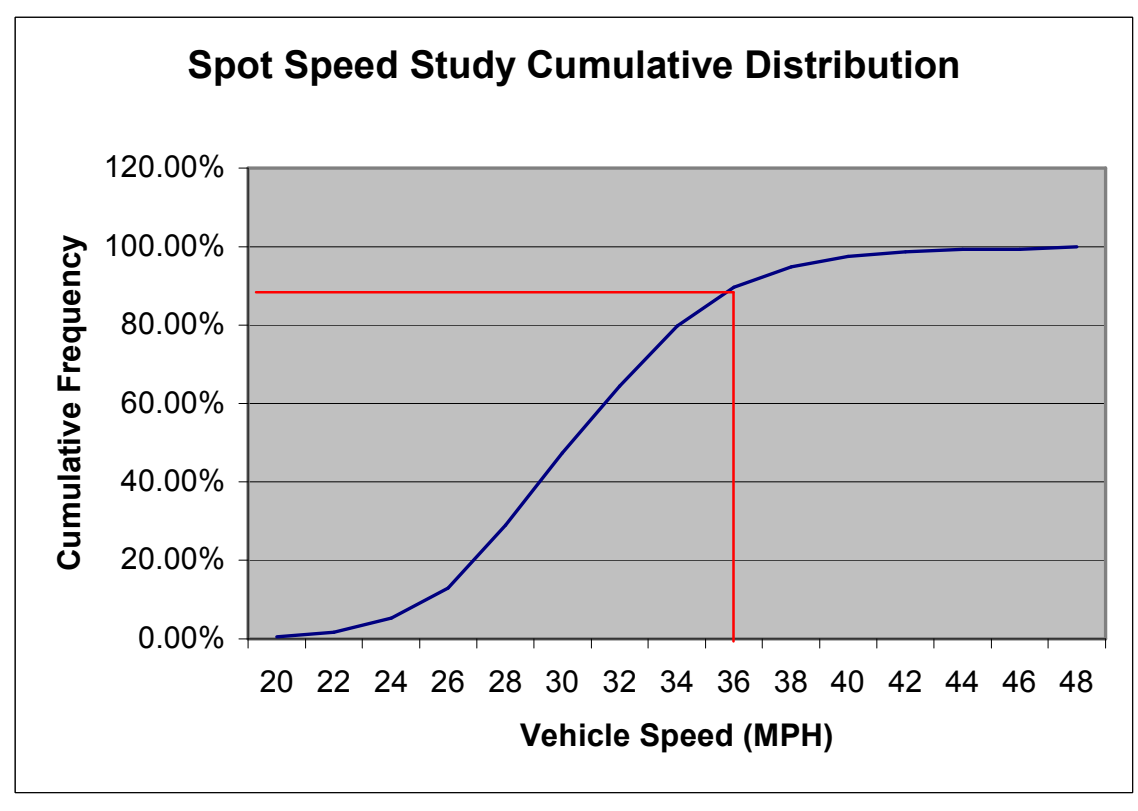




\section{Bridge Project}

The participants are asked to arrive at a predetermined location at an appropriate time in the morning to begin the day's activities. The day begins by discussing structural engineering. This is followed by a workshop on graphical statics. Next, the participants are divided into groups to design a balsa wood truss bridge. Each group is guided through the design of their truss bridge and after approximately an hour, most students have a general configuration for their bridge. With guidelines, rules, a balsa wood kit, and a satisfactory design, each team can begin constructing their bridge. The objective of the activity is to produce the strongest bridge, which is tested using three-point bending on the last day of the program. The group with the strongest bridge wins a prize. For this project, some groups work several days and produce outstanding truss bridges.

\section{Environmental Engineering - Analysis of Water}

The participants are asked to arrive at a predetermined location at an appropriate time in the morning to begin the day's activities. The participants are asked to bring water samples from their home tap, drinking water, and any well water in their town. The testing of the water takes two days. The activity entails testing the water from each participant, for content of chloride, reactive phosphorus, salinity, dissolved oxygen, $\mathrm{pH}$, conductivity, and total dissolved solids.

First, the students must be instructed on laboratory safety procedures and use of equipment for measuring parameters used for establishing drinking water standards. The importance of reading chemical labels, understanding the properties of chemicals, emergency procedures, etc. are stressed in the safety session. After the discussion, the participants are divided into groups. Several workstations are set-up, one for each of the tests. Each group is then taken to one of the workstations to begin the corresponding water test. As each group completes a test at a given workstation, they move on to an open workstation until they complete all the tests. After all the tests are completed, the data collected in the lab is analyzed and compared to the published results from the cities where the water originated.

\section{Field Trips}

Field trips are arranged several weeks in advance. This is done in conjunction with some of the activities. For instance, a visit to a construction site the day following the concrete activity, particularly one where concrete is being poured is scheduled. Also, a visit to a water treatment plant the day after the water analysis is schedule. The main problem with this activity is transportation logistics. Several vehicles must be rented and proper travel paperwork filled out.

\section{Conclusions}

The TAMUK institute has been a tremendous success! The academic and engineering communities have both been enriched as a result of the participation of these fine young people in the activities provided by the TAMUK program. Most of the participants have indicated an interest in pursuing a career in engineering, including 15 for civil engineering. The future success of the institute can be measured by the success of last year's institute, which was the third one offered. The 2004 institute has already produced one college freshman. Also, a past institute 
participant has been recruited as an assistant, Ms. Connie Savvedra. She is in her third year at TAMUK in civil engineering - she will be a civil engineer! It is our hope that we will continue to harvest the fruits of these institutes for years to come.

This past summer was the first time that funding from several sources were pooled to conduct the institute. A number of budgetary issues had to be resolved. The lessons learned from this process include the restrictions on federal and state funds, which do not cover food and other such expenditures. Therefore, private funds such as those from ASCE are critical to provide meals to participants for residential programs. Pooling funding from several private and public sources is critical to be able to provide a complete experience at no cost.

\section{Acknowledgements}

Financial support from the Committee on Diversity and Women in Civil Engineering of the American Society of Civil Engineers, the Civil Engineering Department at Texas A\&M University-Kingsville (TAMUK), and the National Science Foundation through the Center for Research Excellence in Science and Technology at TAMUK is acknowledged. Also, cooperation from the Texas Department of Transportation (TxDOT), the US Army Corps of Engineers, and the Kingsville wastewater treatment plant is greatly acknowledged.

\section{Bibliography}

1. Estrada, H. (2004) CEEN 5316 - FUTURE ENGINEERS SUMMER INSTITUTE, web site, URL: http://users.tamuk.edu/kfhe000/FCESI site/home1.html

2. Kiritsis, N., (1996). "Summer Science Camp at the University of Texas-Pan American." Proceedings of the 1996 Annual Meeting of the Gulf Southwest Section of ASEE, San Antonio, Texas, p. 29-34, held at UTSA,

3. Verner, J. M., and D. J. Ahlgren, (2002). "Fire-Fighting Robot Contest: Interdisciplinary Design Curricula in College and High School.” Journal of Engineering Education, July 2002, p. 355-359.

4. Poole, S.J., J.L. DeGrazia, and J. F. Sullivan, (2001). “Assessing K-12 Pre-Engineering Outreach Programs", Journal of Engineering Education, Jan. 2001, p. 43-48.

5. Garber, N. J., and L. A. Hoel, (1999). Traffic and Highway Engineering, $2^{\text {nd }}$ Edition, PWS Publishing.

\section{Biographical Information}

DR. HECTOR ESTRADA is Associate Professor and Civil Engineering program Coordinator at Texas A\&M University-Kingsville.

DR. PAT LEELANI is Professor of Civil Engineering at Texas A\&M University-Kingsville. 